\section{Diagnóstico da hemoglobina S: análise comparativa do teste de solubilidade com a eletroforese em pH alcalino e ácido no período neonatal}

\section{$S$ Hemoglobin diagnosis: comparative analysis of the solubility test with the electrophoresis in alkaline and acid $\mathrm{pH}$ during the neonatal period}

Flavia Miranda Gomes de Constantino Bandeira 1 Mariana de Carvalho Leal 2 Rafael Rocha Souza 3 Veridiana Câmara Furtado 4 Yara de Miranda Gomes 5

1-3 Fundação de Hematologia e Hemoterapia de Pernambuco (HEMOPE). Rua Joaquim Nabuco, 171. Recife, PE, Brasil. CEP: 52.011-000

4,5 Centro de Pesquisas Aggeu Magalhães. Fundação Oswaldo Cruz. Recife, PE.

\begin{abstract}
Objectives: to evaluate the efficacy of the solubility test as a screening method for hemoglobin $S$ detection in newborns compared to alkaline and acid hemoglobin electrophoresis .

Methods: a total of 1.988 cord blood samples from newborns at Instituto Materno Infantil de Pernambuco (IMIP) during the period of October 1996 to March 1997 were submitted to alkaline hemoglobin electrophoresis and solubility test. Following this, acid hemoglobin electrophoresis was performed as a confirmatory test, when $\mathrm{Hb} \mathrm{S}$ was present in the first two tests mentioned.

Results: Hb S was detected in 105 (5,3\%) of the 1.988 samples by alkaline electrophoresis and were confirmed by acid electrophoresis in 98 (93,3\%). Solubility test has detected $\mathrm{Hb} \mathrm{S}$ in only one sample.

Conclusions: alkaline hemoglobin electrophoresis has been effective for $\mathrm{Hb} \mathrm{S}$ screening in newborn period and can be used in places where more sophisticated techniques are not available. Solubility test must not be used as a screening method in this period of life.
\end{abstract}

Key words Hemoglobin, sickle, Neonatal screening Hemoglobinopathies, Diagnosis

\section{Resumo}

Objetivos: avaliar a eficácia do teste de solubilidade como método de triagem na detecção de $\mathrm{Hb}$ S no período neonatal, comparando-o com as técnicas de eletroforese em $\mathrm{pH}$ alcalino e ácido.

Métodos: o sangue de cordão umbilical de 1.988 recém-nascidos (RN) na maternidade do Instituto Materno-Infantil de Pernambuco (IMIP), durante o período outubro de 1996 a março de 1997, foi submetido à eletroforese de hemoglobina em $\mathrm{pH}$ alcalino $e$ ao teste de solubilidade. A eletroforese de hemoglobina em $\mathrm{pH}$ ácido foi realizada como teste confirmatório em todos os casos em que a eletroforese em $\mathrm{pH}$ alcalino foi positiva para $\mathrm{Hb} \mathrm{S}$ ou $\mathrm{Hb} \mathrm{C}$.

Resultados: a eletroforese de $\mathrm{Hb}$ em $\mathrm{pH}$ alcalino detectou a presença de $\mathrm{Hb}$ S em 105 (5,3\%) amostras. A análise dessas 105 amostras através da eletroforese em pH ácido mostrou que 98 (93,3\%) mantiveram o mesmo padrão eletroforético. $O$ teste de solubilidade detectou apenas um RN portador de $\mathrm{Hb} \mathrm{S}$.

Conclusões: a eletroforese de $\mathrm{Hb}$ em $\mathrm{pH}$ alcalino mostrou-se eficaz no diagnóstico da hemoglobina $S$ no período neonatal, podendo ser utilizada nos locais onde técnicas mais sofisticadas não estão implantadas. O teste de solubilidade não serve como abordagem diagnóstica para a presença de Hb S no período neonatal.

Palavras-chave Hemoglobina falciforme, Triagem neonatal, Hemoglobinopatias, Diagnóstico 


\section{Introdução}

O diagnóstico de hemoglobinopatia S no período neonatal é dificultado pela presença de grande quantidade de hemoglobina fetal (Hb F) quando utilizada a eletroforese em $\mathrm{pH}$ alcalino. $\mathrm{O}$ emprego de eletroforese em $\mathrm{pH}$ ácido visa a reduzir esse problema, pois melhora a condição de separação das frações de hemoglobina, além de separar a fração $\mathrm{S}$ da $\mathrm{D}$, e a C da $\mathrm{E}$, que correm na mesma faixa na eletroforese em $\mathrm{pH}$ alcalino. 1,2

A detecção da $\mathrm{Hb} \mathrm{S}$, quando realizada através da eletroforese em acetato de celulose, deve ser associada a métodos de comprovação, como teste de falcização, prova de solubilidade e eletroforese em pH ácido. A hemoglobina é uma proteína carregada negativamente e a eletroforese de $\mathrm{Hb}$ em $\mathrm{pH}$ alcalino $(8,4$ $8,6)$ parte desse princípio, uma vez que durante a corrida eletroforética essas proteínas migram para o pólo positivo. As hemoglobinas com defeitos estruturais causados por substituições de aminoácidos de diferentes pontos isoelétricos vão apresentar mudanças em suas cargas elétricas, resultando na ocorrência de diferentes mobilidades. 1,3

Devido à grande quantidade de $\mathrm{Hb} \mathrm{F}$ (efeito diluidor) no período neonatal, testes como o de falcização (metabisulfito de sódio) e de solubilidade (ditionito de sódio) freqüentemente resultam em falsos negativos. ${ }^{4}$ Esse último apresenta uma boa sensibilidade para a triagem de $\mathrm{Hb} \mathrm{S}$ em outras faixas etárias, e segundo Louderback et al. 5 e Surve et al. 6 chega a uma acurácia de $99,8 \%$ na identificação desta $\mathrm{Hb}$. Ainda oferece custo bem mais baixo do que a eletroforese e é de fácil execução. O teste de solubilidade baseia-se no fato de que, sob baixas concentrações de oxigênio, a $\mathrm{Hb} \mathrm{S}$ torna-se 100 vezes menos solúvel que sua forma oxigenada. ${ }^{3}$

No entanto, o teste de solubilidade não apresenta boa sensibilidade para detecção da presença de $\mathrm{Hb} \mathrm{S}$ no período neonatal, especialmente nos RN prematuros, uma vez que neste período ainda não houve a transição de $\mathrm{Hb} \mathrm{F}$ para hemoglobina do adulto. Nessa faixa etária até mais ou menos os seis meses de idade, um teste de solubilidade negativo deve ser interpretado com cautela, principalmente se feito por ocasião de uma situação de emergência. ${ }^{7}$

O presente trabalho teve como objetivo avaliar a eficácia do teste de solubilidade como método de triagem na detecção de $\mathrm{Hb} \mathrm{S}$ no período neonatal comparando-o com as técnicas de eletroforese em pH alcalino e ácido.

\section{Métodos}

As amostras testadas foram obtidas na maternidade do Instituto Materno-Infantil de Pernambuco (IMIP), Recife, Brasil, durante o período outubro de 1996 a março de 1997. O protocolo utilizado no presente trabalho foi aprovado pela Comissão de Ética do IMIP.

O sangue de cordão umbilical de 1.988 recémnascidos (RN), na quantidade mínima de $1 \mathrm{ml}$ e máxima de $5 \mathrm{ml}$, foi coletado e colocado em um tubo contendo EDTA a 5\%. As amostras foram armazenadas a $4{ }^{\circ} \mathrm{C}$ por um período máximo de sete dias, quando foram submetidas a eletroforese de hemoglobina em $\mathrm{pH}$ alcalino e ao teste de solubilidade. A eletroforese de hemoglobina em $\mathrm{pH}$ ácido foi também realizada como teste confirmatório em todos os casos em que a eletroforese em $\mathrm{pH}$ alcalino foi positiva para $\mathrm{Hb} \mathrm{S}$ ou $\mathrm{Hb} \mathrm{C}$.

Para o teste de solubilidade, $200 \mu 1$ de sangue foram colocados em cada poço de uma placa de microtitulação, adicionando-se em seguida $50 \mathrm{ml}$ da solução hemolisante constituída de $10 \mathrm{mg}$ de $\mathrm{Na}_{2} \mathrm{~S}_{2} \mathrm{O}_{4}$ para cada $\mathrm{ml}$ da solução fosfato $\left(\mathrm{K}_{2} \mathrm{HPO}_{4}\right.$ $29,66 \mathrm{~g} ; \mathrm{KH}_{2} \mathrm{PO}_{4}-16,89 \mathrm{~g}$; saponina - $1,25 \mathrm{~g} ; 125 \mathrm{ml}$ de água destilada). Após homogeneização, $20 \mathrm{ml}$ foram removidos e aplicados em papel filtro Whatman $n^{\circ} 6.3$ A leitura do teste foi feita a olho nu, um a dois minutos após a aplicação do hemolisado no papel de filtro, sendo que no caso positivo observou-se o centro escuro com um halo mais claro.

A eletroforese em $\mathrm{pH}$ alcalino foi realizada utilizando-se os seguintes materiais procedentes do HELENA Laboratories: Titan III (76 x 60mm - Hemoglobina) -Cód. 3022; Tampão Supre-Heme - Cód. 5802; Titan Gel Chamber - Cód. 4063; Super Z 8 Kit aplicador - Cód. 4088; Ponceau S - Cód. 5526; Clair Aid - solução transparentizadora acetato de celulose - Cód. 5005. O sangue do cordão umbilical foi hemolisado com saponina a $1 \%$ na proporção de 1:3, respectivamente. Como controle, amostra de sangue AS (Hb AS) foi utilizada. Após 10 minutos o hemolisado foi depositado na membrana de acetato de celulose. A eletroforese foi realizada à temperatura ambiente, com uma voltagem de $280 \mathrm{~V}$ por 20 minutos. As proteínas foram coradas com Ponceau S. ${ }^{3}$ A leitura do teste foi feita a olho nu imediatamente após a coloração da placa, onde foram observadas as bandas protéicas e comparadas com o controle, aplicado em todas as corridas eletroforéticas.

A eletroforese em $\mathrm{pH}$ ácido foi realizada segundo Naoum. ${ }^{3} \mathrm{O}$ hemolisado obtido após tratamento das hemácias com a solução hemolisante (saponina $1 \mathrm{~g} ; \mathrm{KCN}-10 \mathrm{mg} ; \mathrm{H}_{2} \mathrm{O}-100 \mathrm{ml}$ ), na proporção de 
2:1, respectivamente, foi aplicado sobre uma lâmina contendo ágar-gel (Bacto-agar-Difco) a $1 \%$ em tampão fosfato 6,2. A eletroforese foi processada com uma voltagem constante de $150 \mathrm{~V}$ durante 15 minutos e as proteínas coradas com amido black a $1 \%$ em ácido acético a $10 \%$. A leitura do teste, também a olho nu, foi feita após remoção do excesso do corante, sendo observadas as bandas protéicas também comparadas com um controle AS.

\section{Resultados}

A Figura 1 mostra o perfil eletroforético representativo de $\mathrm{Hb}$ em $\mathrm{pH}$ alcalino das 1.988 amostras analisadas. Destas, $105(5,3 \%)$ apresentavam presença de Hb S. Dos 105 RN que apresentaram presença de $\mathrm{Hb} \mathrm{S}$ na eletroforese em $\mathrm{pH}$ alcalino, 98 $(93,3 \%)$ mantiveram o mesmo padrão eletroforético após o teste confirmatório com pH ácido (Figura 2). As sete $(6,7 \%)$ amostras restantes não foram confirmadas $\mathrm{Hb} \mathrm{S}$ positivas, sendo os resultados considerados falso-positivos no processo de triagem.

Eletroforese de hemoglobina $(\mathrm{Hb})$ em $\mathrm{pH}$ alcalino realizada em sangue de cordão umbilical. Amostra representativa dos recém-nascidos no Instituto Materno Infantil de Pernambuco (IMIP) examinados entre outubro de 1996 a março de 1997. 1: controle AS; 2, 3, 4, 5, 6 e 8: FA; 7: FAS. AS = Hb A e HbS; FA = Hb F e Hb A; FAS = HbF, HbA e HbS.

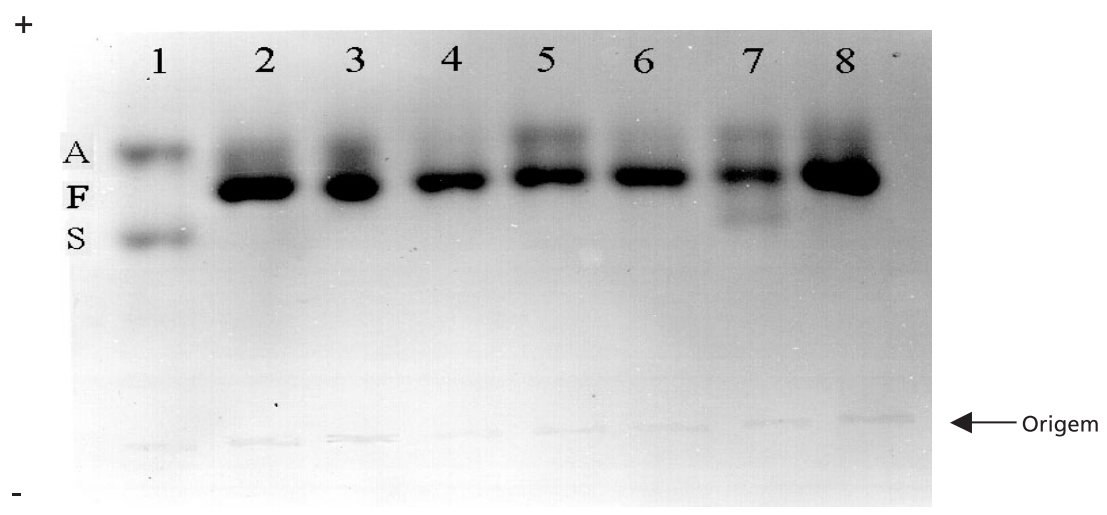

\section{Figura 2}

Eletroforese de hemoglobina $(\mathrm{Hb})$ em pH ácido realizada em sangue de cordão umbilical. Amostra representativa dos recém-nascidos no Instituto Materno Infantil de Pernambuco (IMIP) entre outubro de 1996 a março de 1997. 1:

controle AS; 5: SC; 14: FA; 2, 3, 4, 6, 7, 8, 9, 10, 11, 12 e 13: FAS. AS = HbA e HbS, SC = HbS e HbC, FA = Hb F e Hb A, $\mathrm{FAS}=\mathrm{HbF}, \mathrm{HbA}$ e $\mathrm{HbS}$.

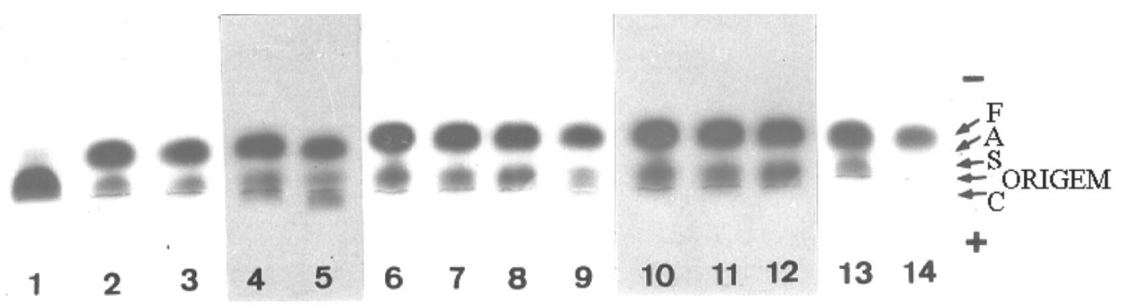


Teste de solubilidade realizado em sangue de cordão umbilical. Amostra representativa dos recém-nascidos no Instituto Materno Infantil de Pernambuco (IMIP) entre outubro de 1996 a março de 1997. CONT: controle positivo; 1157: amostra positiva; demais: amostras negativas.

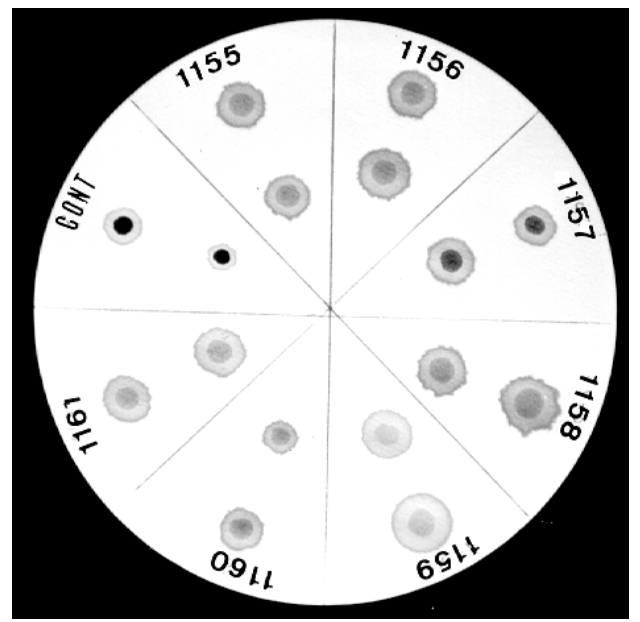

O teste de solubilidade detectou apenas uma $(0,9 \%)$ amostra positiva para $\mathrm{Hb} \mathrm{S}$ (Figura 3 ), apresentando portanto, uma elevada percentagem de resultados falso-negativos $(99,1 \%)$. Nenhum resultado falso-positivo foi observado. Pretendia-se calcular sensibilidade e especificidade do teste de solubilidade, tomando como padrão ouro a eletroforese de hemoglobina em $\mathrm{pH}$ alcalino, mas devido ao resultado acima esses cálculos não puderam ser realizados.

\section{Discussão}

As técnicas laboratoriais empregadas para a detecção de $\mathrm{Hb} \mathrm{S}$ em sangue de cordão umbilical no presente estudo foram as mais simples e nem por isso menos sensíveis. A eficácia da eletroforese de $\mathrm{Hb} \mathrm{em} \mathrm{pH}$ alcalino seguida de eletroforese de $\mathrm{Hb}$ em $\mathrm{pH}$ ácido para a detecção de hemoglobinopatias em sangue de cordão umbilical tem sido demonstrada por vários

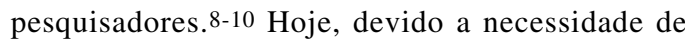
maior rapidez e manutenção da eficácia, os programas de triagem neonatal vêm utilizando eletroforese através da focalização isoelétrica (FIE) e cromatografia líquida de alta pressão (HPLC). ${ }^{11}$

De acordo com o American Academy of Pediatrics 12 é desconhecida a taxa de falso-negativos dos testes de screening utilizados, pois geralmente os testes empregados na triagem, quando negativos, não são rotineiramente repetidos. É atribuída sensibilidade de 93,2\% para a eletroforese em ágar-citrato e $100 \%$ para a focalização isoelétrica. 12 A taxa de falso-positivos nos testes de triagem (focalização isoelétrica, eletroforese em acetato de celulose seguida de eletroforese em ágar-citrato ou HPLC) é de 1:3.000; 97,9\% dos resultados positivos são confirmados posteriormente. 12

Serjeant et al. ${ }^{8}$ publicaram o relato da análise de 8.000 amostras de sangue de cordão umbilical de RN de uma maternidade da Jamaica e concluíram que a freqüência gênica e a freqüência fenotípica são correlatas usando eletroforese em $\mathrm{pH}$ alcalino seguida pela eletroforese em $\mathrm{pH}$ ácido nos casos positivos.

Kramer et al. ${ }^{9}$ estudando amostras de sangue de cordão umbilical de RN de mães negras assistidas no Yale, New Haven Hospital, afirmam que durante os 65 primeiros meses após o início da triagem, nasceram 3.976 crianças negras e dessas, 138 apresentaram hemoglobinas anormais na triagem com eletroforese em $\mathrm{pH}$ alcalino seguida pela eletroforese em $\mathrm{pH}$ ácido. Todos os casos positivos foram confirmados durante o seguimento dessas crianças (três a cinco anos depois), quando foram repetidas novas eletroforeses de hemoglobina, dosagem de hemoglo- 
bina fetal e estudos familiares.

No Brasil, Ruiz et al. 10 analisaram em Santos, SP, 2.281 amostras de sangue de cordão umbilical do ponto de vista eletroforético e comentam as vantagens da eletroforese de $\mathrm{Hb}$ em $\mathrm{pH}$ alcalino seguida pela eletroforese em $\mathrm{pH}$ ácido em nosso meio, uma vez que métodos mais sofisticados podem significar aumento de custo, além de trazer implicações do ponto de vista ético. Isto porque, caso seja feito diagnóstico ante-natal através de análise de DNA, não há em nosso país legislação que adote a interrupção da gestação como solução.

Estudando os RN no IMIP, a eletroforese de $\mathrm{Hb}$ em $\mathrm{pH}$ alcalino, seguida de eletroforese em $\mathrm{pH}$ ácido (nos casos positivos na triagem), mostrou-se adequada ao objetivo proposto, uma vez que após realização do teste confirmatório, 98 (93,3\%) dos 105 RN positivos mantiveram o padrão eletroforético encontrado na triagem. Os sete RN restantes não foram confirmados como positivos, tendo sido portanto considerados como falso-positivos durante a triagem. Por outro lado, o teste de solubilidade detectou apenas um RN portador de $\mathrm{Hb} \mathrm{S}$, não de- tectando as demais amostras positivas, assim como não apresentou resultado falso-positivo. $\mathrm{O}$ teste de solubilidade, apesar de ser uma técnica de baixo custo, fácil execução e sensível quando usada em maiores de 12 meses de idade. ${ }^{3,13}$ não se mostrou útil para a triagem de $\mathrm{Hb} \mathrm{S}$ em sangue de cordão umbilical, que é rico em $\mathrm{Hb}$ fetal, como previamente demonstrado por Louderback et al. ${ }^{5}$ e Capps-Jenner. ${ }^{7}$

De acordo com Powars ${ }^{14}$ o método de seleção para o diagnóstico de hemoglobinopatias no RN deve ser baseado na experiência do local onde vai ser realizado, no custo implicado e na aceitação familiar dos procedimentos oferecidos.

Técnicas como eletroforese através de focalização isoelétrica, HPLC, análise de DNA em material obtido através de punção de vilosidade coriônica, entre outras, têm sido usadas também em estudos populacionais em locais onde esses exames são disponíveis. No entanto não colocam os métodos empregados neste trabalho fora de uso, já que inúmeros autores apresentam resultados adequados usando estes dois métodos. $4,9,15-18$

\section{Agradecimentos}

Os autores agradecem à Coordenação de Aperfeiçoamento Pessoal de Nível Superior (CAPES), à Fundação de Amparo à Ciência e Tecnologia do Estado de Pernambuco (FACEPE), ao Conselho Nacional de Desenvolvimento Científico e Tecnológico (CNPq), à Fundação Oswaldo Cruz (FIOCRUZ) e à Helena Laboratories pelo apoio financeiro.

\section{Referências}

1. Naoum PC, editor. Eletroforese: técnicas e diagnósticos. São Paulo: Santos; 1990, p. 91

2. Naoum PC, editor. Hemoglobinopatias e talassemias. São Paulo: Sarvier; 1997 , p. 144-171.

3. Naoum PC, editor. Diagnóstico das hemoglobinopatias. São Paulo: Sarvier; 1987, 161-192.

4. Pearson HA. A neonatal programme for sickle cell anemia. Adv Pediatr 1986; 33: 381-400.

5. Louderback AL, Youhne Y, Fontana A, Natland M. Clinical evaluation of a rapid screening test for sickle cell trait (S) and sickle cell anemia (SS). Clin Chem 1974; 20: 761-4.
6. Surve RR, Mukherjee MB, Kate SL, Nagtilak SB, Wadia M, Tamankar AA, Ghosh K, Colah RB, Mohanty D. Detection of the beta s gene: na evaluation of the solubility test against automated chromatography and hemoglobin electrophoresis. Br J Biome Sci 2000;57:292-94.

7. Capps-Jenner AE, coordinator. Investigation of the micromethod for $\mathrm{Hb}$ "S" detection as used in Brazil. London: Whittington Hospital; 1994.

8. Serjeant BE, Forbes M, Williams LL, Serjeant GR Screening cord bloods for detection of sickle cell disease in Jamaica. Clin Chem 1974; 20: 666-9. 
9. Kramer MS, Rooks Y, Jonhston D, Pearson H. Accuracy of cord blood screening for sickle hemoglobinopathies three to five years follow up. JAMA 1979; 241: 485-6.

10. Ruiz MA, Guerra CC, Naoum PC. Detecção de hemoglobinas anormais em sangue de cordão de recém-nascidos na cidade de Santos, SP, através de eletroforese em gel de ágar amido. Bol Soc Bras Hematol Hemoter 1986; 8: 813

11. Old JM. Screening and genetic diagnosis of hemoglobin disorders. Blood Reviews 2003; 17: 43-63.

12. American Academy of Pediatrics. Committee on Genetics. Newborn screening fact sheets. Pediatrics 1996; 98: 473 501.

13. Lima AA, Albuquerque LM, Lins MS, Bezerra TM. Hemoglobina S: estudo de uma família. Rev Bras Anal Clin 1984; 16: 1-3.

14. Powars D. Diagnosis at birth improves survival of children with sickle cell anemia. Pediatrics 1989; 83: 830-33.
15. Headings VE. Sickle cell disease in childhood-strategies for early diagnosis. Am J Pediatr Hematol Oncol 1982; 4: $67-71$.

16. Ibarra GH, Zayas MA, Suardiaz B, Balea AD, Ruiz MM Eficiência del programa de prevencion de la anemia por hematies falciformes (AHF) en ciudad de la Habana, en el periodo de enero a diciembre de 1986. Rev Cuba Pediatr 1989; 61: 107-12.

17. Naoum PC, Domingos CRB. Atualização de técnicas para hemoglobinopatias. São José do Rio Preto: Universidade do Estado de São Paulo; 1995.

18. Bandeira FMG, Leal MC, Souza RR, Furtado VC, Gomes YM, Marques NM. Características de recém-nascidos portadores de hemoglobina "S" detectados através de triagem em sangue de cordão umbilical. J Pediatr [Rio de Janeiro] 1999; 75: 167-71.

Recebido em 14 de maio de 2003

Versão final reapresentada em 8 de agosto de 2003

Aprovado em 26 de agosto de 2003 